\title{
Downregulation of the expression of HDGF attenuates malignant biological behaviors of hilar cholangiocarcinoma cells
}

\author{
YANFENG LIU ${ }^{1}$, JINGXIAN SUN ${ }^{2}$, GUANGYUN YANG $^{3}$, ZHAOJIAN LIU $^{4}$, SEN GUO ${ }^{1}$, \\ RUI ZHAO ${ }^{1}, \mathrm{KESEN} \mathrm{XU}^{1}, \mathrm{XIAOPENG} \mathrm{WU}^{1}$ and ZHAOYANG ZHANG ${ }^{5}$ \\ ${ }^{1}$ Department of Hepatobiliary Surgery, Qilu Hospital of Shandong University, Jinan, Shandong 250012; ${ }^{2}$ Department of \\ Surgery, Affiliated Hospital of Shandong University of Traditional Chinese Medicine, Jinan, Shandong 250011; \\ ${ }^{3}$ Department of Hepatobiliary Surgery, The General Hospital of PLA, Beijing 100853; ${ }^{4}$ Institute of Cell Biology, \\ Shandong University School of Medicine; ${ }^{5}$ Department of Emergency Surgery, \\ Qilu Hospital of Shandong University, Jinan, Shandong 250012, P.R. China
}

Received August 30,2014; Accepted May 13, 2015

DOI: $10.3892 / \mathrm{mmr} .2015 .3922$

\begin{abstract}
Hepatoma-derived growth factor (HDGF) has been reported to be a potential predictive and prognostic marker for several types of cancer and important in malignant biological behaviors. However, its role in human hilar cholangiocarcinoma remains to be elucidated. Our previous study demonstrated that high expression levels of HDGF in hilar cholangiocarcinoma tissues correlates with tumor progression and patient outcome. The present study aimed to elucidate the detailed functions of the HDGF protein. This was performed by downregulating the protein expression of HDGF in the FRH0201 hilar cholangiocarcinoma cell line by RNA interference (RNAi) in vitro, and revealed that downregulation of the HDGF protein significantly inhibited the malignant biological behavior of the FRH0201 cells. In addition, further investigation revealed that downregulation of the protein expression of HDGF significantly decreased the secretion of vascular endothelial growth factor, which may be the mechanism partially responsible for the inhibition of malignant biological behaviors. These findings demonstrated that HDGF is important in promoting malignant biological behaviors, including proliferation, migration and invasion of hilar cholangiocarcinoma FRH0201 cells. Inhibition of the expression of HDGF downregulated the malignant biological behaviors, suggesting that downregulation of the protein expression of HDGF by RNAi may be a novel therapeutic approach to inhibit the progression of hilar cholangiocarcinoma.
\end{abstract}

Correspondence to: Professor Zhaoyang Zhang, Department of Emergency Surgery, Qilu Hospital of Shandong University, 107 Wenhuaxi Road, Jinan, Shandong 250012, P.R. China

E-mail: zhang_zhao_yang@126.com

Key words: hilar cholangiocarcinoma, hepatoma-derived growth factor, malignant biological behaviors, small interfering RNA

\section{Introduction}

Hilar cholangiocarcinoma is a life threatening malignancy, which is difficult to diagnose and is associated with high mortality rates (1). Surgery, either in the form of liver resection or liver transplantation, is the only effective curative therapy for hilar cholangiocarcinoma $(2,3)$ and only $50-70 \%$ of the patients who undergo surgery are candidates for curative resection (4), however, the recurrence rates remain high even following curative resection (5). Adjuvant therapy, including chemotherapy and radiation therapy, has not been confirmed to reduce the risk of recurrence (6). Therefore, identifying novel biomarkers, which are involved in tumor development and progression may assist in improving therapeutic strategies and patient outcomes.

Hepatoma-derived growth factor (HDGF), as a member of the heparin-binding growth factors, was originally purified from cultured media with the HuH-7 human hepatoma cell line $(7,8)$. Previous studies have demonstrated that HDGF is upregulated in various types of malignancy and is predictive of a poor survival outcome, and that HDGF possesses aggressive biological behaviors in vitro, including proliferation, migration, invasiveness and angiogenesis (9-12). However, the correlation between the malignant behaviors and HDGF in the hilar cholangiocarcinoma cell line remains to be fully elucidated.

The present study was designed to clarify the malignant behaviors of the FRH0201 human hilar cholangiocarcinoma cell line by using small interfering (si)RNA in vitro, and aimed to provide novel experimental evidence for the targeted therapy of human hilar cholangiocarcinoma.

\section{Materials and methods}

Cell lines and cell culture. The human FRH0201 hilar cholangiocarcinoma cell line was provided by Professor Xiaopeng Wu (Qilu Hospital of Shandong University, Jinan, China). The cells were incubated in Dulbecco's modified Eagle's medium (DMEM), supplemented with $10 \%$ heat-inactivated fetal bovine serum (FBS; Invitrogen Life Technologies, Carlsbad, $\mathrm{CA}$, USA), at $37^{\circ} \mathrm{C}$ with $5 \% \mathrm{CO}_{2}$. 
siRNA transfection. The sequence of the siRNA targeting HDGF (5'-AACCGGCAGAAGGAGUACAAA-3') used was adopted from a previous study (10). The HDGF siRNA and negative control siRNA were chemically synthesized by GenePharma Co., Ltd. (Shanghai, China). The corresponding cells were divided as follows: Control, negative-siRNA and HDGF-siRNA group. In vitro transfections were performed using Lipofectamine RNAiMax (Invitrogen Life Technologies), according to the manufacturer's instructions. All siRNAs were dissolved in sterilized and RNase-free water at a final concentration of $20 \mathrm{mM}$. Briefly, the FRH0201 cells were seeded in a six-well plate at a density of $5 \times 10^{5}$ cells/well at $37^{\circ} \mathrm{C}$ with $5 \% \mathrm{CO}_{2}$ and were incubated until they reached $80 \%$ confluence. The cells were incubated in the siRNA-Lipofectamine complex-containing medium for $6 \mathrm{~h}$, following which the medium was replaced with DMEM containing $10 \% \mathrm{FBS}$ at $37^{\circ} \mathrm{C}$ with $5 \% \mathrm{CO}_{2}$. The cells were incubated for $48 \mathrm{~h}$ and were then harvested for analysis of the mRNA and protein expression levels of HDGF.

Reverse transcription-quantitative polymerase chain reaction (RT-qPCR). The total RNA was extracted from the FRH0201 cells in 96-well plates (seeded at a density of $2 \times 10^{3} / 200 \mu \mathrm{l}$ ) using TRIzol reagent (Takara Bio, Inc., Tokyo, Japan). The quantity of total RNA was $2 \mu \mathrm{g}$ as per the instructions. First strand cDNA was synthesized from the mRNA using a Primescript ${ }^{\mathrm{TM}}$ RT reagent kit (Takara, Bio., Inc.), and the RT-qPCR was performed using a SYBR Green PCR kit (Takara, Bio., Inc.) on a Light Cycler system 2.0 (Roche Diagnostics, Mannheim, Germany). The sequence of the primers (GenePharma Co., Ltd., Shanghai, China) used were as follows: HDGF, sense 5'-CAGCCAACAAATACCAAGTCT-3' and antisense 5'-GTT CTCGATCTCCCACAGC-3', and GAPDH, sense 5'-GGT GGTCTCCTCTGACTTCAACA-3' and antisense 5'-GTT GCTGTAGCCAAATTCGTTGT-3'. The PCR conditions were as follows: Initial denaturation at $95^{\circ} \mathrm{C}$ for $10 \mathrm{sec}$, followed by 45 cycles at $95^{\circ} \mathrm{C}$ for $5 \mathrm{sec}, 60^{\circ} \mathrm{C}$ for $30 \mathrm{sec}$ and $72^{\circ} \mathrm{C}$ for $10 \mathrm{sec}$. The comparative threshold cycle $(\mathrm{Ct})$ method $\left(2^{-\Delta \Delta \mathrm{Ct}}\right)$ was used to analyze the relative changes in gene expression and the levels were normalized against GAPDH (13). The experiment was repeated twice with triplicate measurements in each experiment.

Western blot analysis. All the grouped cells were harvested and rinsed twice with phosphate-buffered saline (PBS). The total cellular protein was extracted using a Nuclear and Cytoplasmic Protein Extraction kit (Beyotime Institute of Biotechnology, Shanghai, China). Following extraction, the protein concentration was measured using an Enhanced BCA Protein Assay kit (Beyotime Institute of Biotechnology), and an equal quantity of protein $(30 \mu \mathrm{g})$ from each group was subjected to $10 \%$ SDS-PAGE (Beyotime Institute of Biotechnology). The proteins were subsequently transferred onto polyvinylidene fluoride (PVDF) membranes (EMD Millipore, Billerica, MA, USA). Following blocking with Tris-buffered saline with Tween-20 ( $\mathrm{pH}$ 7.6; Beyotime Institute of Biotechnology), containing $5 \%$ non-fat milk for $2 \mathrm{~h}$ at room temperature, the PVDF membranes were incubated with rabbit anti-humanHDGF polyclonal antibody (1:100; Proteintech Group, Inc., Chicago, USA) and rabbit anti-human $\beta$-actin monoclonal antibody
(1:1,000; Santa Cruz Biochemistry, Inc., Santa Cruz, CA, USA) overnight at $4^{\circ} \mathrm{C}$. The membranes were subsequently incubated for $1 \mathrm{~h}$ with horseradish peroxidase-conjugated secondary antibody (1:1,000; Beyotime Institute of Biotechnology) at room temperature. The immunoreactive bands were visualized using a Chemilluminescent ECL Detection system (EMD Millipore), according to the manufacturer's instructions. The intensity of each band was quantified using ImageJ software version 1.43 (National Institutes of Health, Bethesda, MD, USA). The experiment was repeated twice with triplicate measurements in each experiment.

3-(4,5-dimethyl-2-thiazolyl)-2,5-diphenyl-2-H-tetrazolium bromide (MTT) assay. Prior to siRNA transfection, $10^{4}$ cells were seeded into a 96-well plate (200 $\mu \mathrm{l} /$ well), with three wells for each group. At $48 \mathrm{~h}$ post-transfection, MTT $(5 \mathrm{mg} / \mathrm{ml}$; $20 \mu \mathrm{l} /$ well; Beyotime Institute of Biotechnology) was added and the cells were cultured at $37^{\circ} \mathrm{C}$ for $4 \mathrm{~h}$. Following discarding of the supernatant, the cells were mixed with dimethyl sulfoxide (150 $\mu \mathrm{l} /$ well; Beyotime Institute of Biotechnology) for $10 \mathrm{~min}$. The absorbance of each well was measured at $570 \mathrm{~nm}$ (A570) using an ultraviolet spectrophotometer, UV9100 (LabTech, Inc., Beijing, China) and the cell proliferation rate was calculated.

Wound healing migration assay. Briefly, the cells in each group were seeded into a 12 -well plate, at equal densities, in complete medium and were incubated at $37^{\circ} \mathrm{C}$ with $5 \% \mathrm{CO}_{2}$ until the cells had grown to $80 \%$ confluence. Scratching wounds of an identical width were created in the monolayer using a sterile pipette tip. The wells were rinsed with PBS three times to remove floating cells and debris, and the remaining cells were cultured in serum-free DMEM, with the culture plates incubated at $37^{\circ} \mathrm{C}$ and in $5 \% \mathrm{CO}_{2}$. Following incubation, wound healing was measured and images were captured with a light microscope Olympus IX81 (Olympus, Tokyo, Japan) at 0, 8 and $16 \mathrm{~h}$. The experiment was repeated twice with triplicate measurements in each experiment.

Transwell invasion assay and migration assay. The invasive capability of tumor cells was determined using Matrigel-coated Transwell invasion chambers ( $8 \mu \mathrm{m}$ pore size; BD Biosciences, Bedford, MA, USA). At 48 h post-siRNA treatment, the cells in the groups were collected and $10^{5}$ cells from each group were added to upper Transwell chambers in $100 \mu$ l serum-free medium. The lower chamber was filled with $500 \mu 1$ DMEM, containing $10 \% \mathrm{FBS}$. Following incubation at $37^{\circ} \mathrm{C}$ for $24 \mathrm{~h}$, the cells that had invaded through the membrane were fixed with methanol for 10 min, stained with Trypan blue (Beyotime Institute of Biotechnology) for $10 \mathrm{~min}$ and counted under a light microscope Olympus IX81 (Olympus). The migration assay were performed in a similar manner, using a Transwell chamber without Matrigel, and incubation conditions were $37^{\circ} \mathrm{C}$ for $16 \mathrm{~h}$. Triplicate measurements were performed in each experiment.

Enzyme-linked immunosorbent assay (ELISA). The cells from all the groups were seeded into six-well plates $\left(5 \times 10^{5}\right.$ cells/well $)$ and cultured in serum-free DMEM for $24 \mathrm{~h}$ at $37^{\circ} \mathrm{C}$ with $5 \%$ $\mathrm{CO}_{2}$. The supernatant was collected, centrifuged at $1,000 \mathrm{xg}$ for $15 \mathrm{~min}$ at $4^{\circ} \mathrm{C}$, filtered through a $0.22 \mathrm{~mm}$ filter (EMD Millipore) and stored at $-80^{\circ} \mathrm{C}$ until use. Additionally, the 
supernatant levels of vascular endothelial growth factor (VEGF) were detected using a VEGF ELISA kit (Pierce Biotechnology, Rockford, IL, USA), to recognize VEGF165 and VEGF121. The ELISA was performed, according to the manufacturer's instructions. The concentrations of VEGF in the supernatant was measured in duplicate.

Statistical analysis. All results are presented as the mean \pm standard deviation. Statistical analysis was performed using SPSS 13.0 software (SPSS, Inc., Chicago, IL, USA). The differences between groups were assessed using Student's t-test. $\mathrm{P}<0.05$ was considered to indicate a statistically significant difference.

\section{Results}

HDGF siRNA effectively suppresses the $m R N A$ and protein expression levels of HDGF. siRNA targeting HDGF was used to decrease the mRNA expression levels of HDGF in the FRH0201 cells. RT-qPCR revealed that the mRNA expression of HDGF was markedly decreased to $25.3 \%$ by the HDGF siRNA at $48 \mathrm{~h}$ post-transfection, compared with the control group $(\mathrm{P}<0.01$; Fig. 1A). Similarly, western blot analysis demonstrated that the protein expression of HDGF was inhibited to $34.9 \%$ of that observed in the control group $(\mathrm{P}<0.01$; Fig. $1 \mathrm{~B}$ and $\mathrm{C})$. This confirmed that HDGF siRNA effectively inhibited the expression of its target gene, HDGF, at the transcriptional and translational levels.

Downregulation of the expression of HDGF decreases the proliferative ability of FRHO2O1 cells. The results of the MTT assay revealed that the proliferative ability of the FRH0201 cells treated with HDGF siRNA was $46.0 \%$ of that observed in the control cells 48 h post-transfection $(\mathrm{P}<0.01$; Fig. 1D).

Downregulation of the expression of HDGF inhibits the migratory ability of FRHO2O1 cells. In the present study, a cell wound healing migration assay and a Transwell migration assay were used to detect the migratory ability of tumor cells in vitro. In the cell wound healing migration assay, no statistical difference was observed between the groups, although the migratory ability was decreased $8 \mathrm{~h}$ post-transfection with HDGF siRNA. By contrast, the migratory ability of the HDGF siRNA group was significantly decreased at $16 \mathrm{~h}$ post-transfection, and was $41.7 \%$ of that observed in the control cells $(\mathrm{P}<0.05$ : Fig. 2$)$. In addition, the Transwell migration assay confirmed in, three-dimensional culture medium, that the migration of the cells transfected with HDGF siRNA was inhibited and the number of migrating cells was $26.5 \%$ of that observed in the control cells $(\mathrm{P}<0.01$; Fig. 3$)$.

Downregulation of the expression levels of HDGF inhibits the invasive ability of FRHO2O1 cells. The Transwell invasion assay revealed that the invasive ability of the cells transfected with HDGF siRNA was inhibited. The number of invading cells was $22.7 \%$ of that observed in the control cells $(\mathrm{P}<0.01$; Fig. 3$)$.

Downregulation of the protein expression of HDGF inhibits the secretion of VEGF in FRHO2O1 cells. The levels of VEGF, which were detected in the supernatants of the different
$\mathbf{A}$

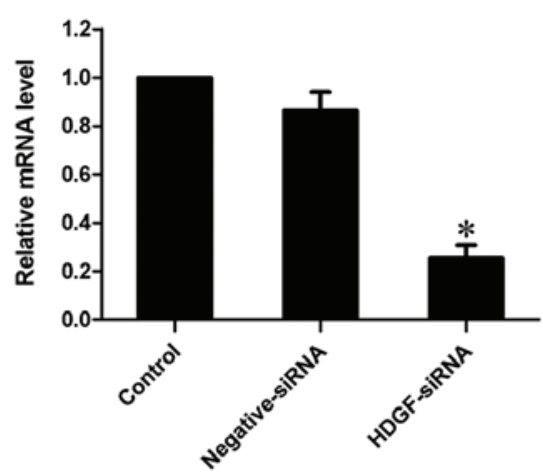

B

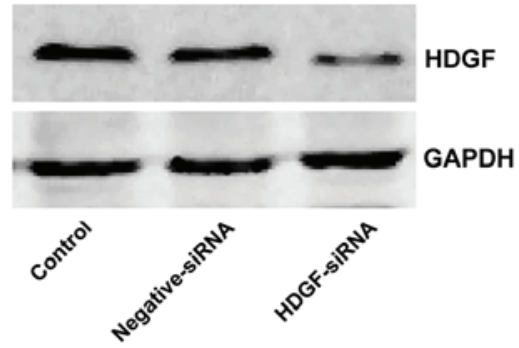

C

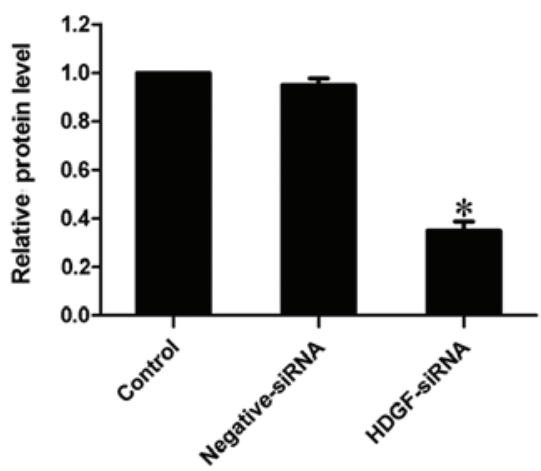

D

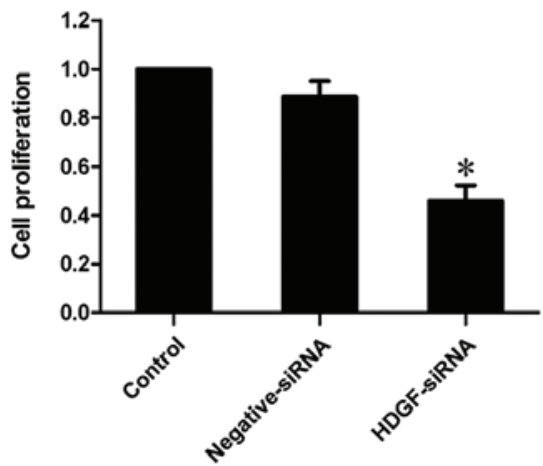

Figure 1. Following siRNA transfection into hilar cholangiocarcinoma cells, the changes in the mRNA and protein expression levels of HDGF were recorded. (A) Results of the reverse transcription-quantitative polymerase chain reaction analysis revealed that the mRNA expressions levels of HDGF were markedly decreased to $25.3 \%$ by transfection with HDGF siRNA at $48 \mathrm{~h}$ post-transfection, compared with the control group ( $(\mathrm{P}<0.01)$. (B and C) Results of the western blot analysis revealed that the protein expression of HDGF was inhibited to $34.9 \%$ of that observed in the control group ("P<0.01). (D) A 3-(4,5-dimethyl-2-thiazolyl)-2,5-diphenyl-2-H-tetrazolium bromide assay revealed that the proliferative ability of the FRH0201 cells transfected with HDGF siRNA was only $46.0 \%$ of that observed in the control cells $48 \mathrm{~h}$ after transfection ( $\mathrm{P}<0.01)$. Data are presented as the mean \pm standard deviation. HDGF, hepatoma-derived growth factor; siRNA, small interfering RNA 
A
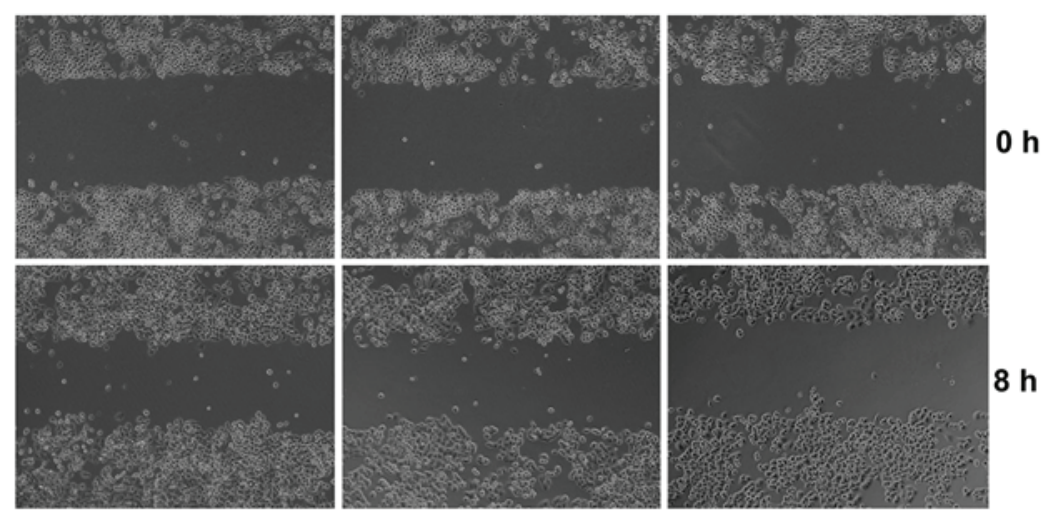

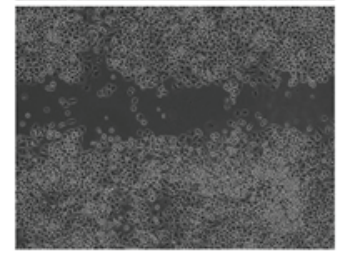

Control

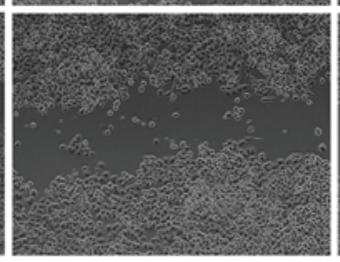

Negative control

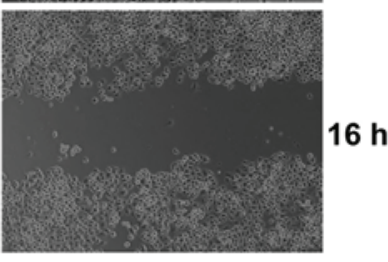

HDGF-siRNA

$\mathbf{B}$

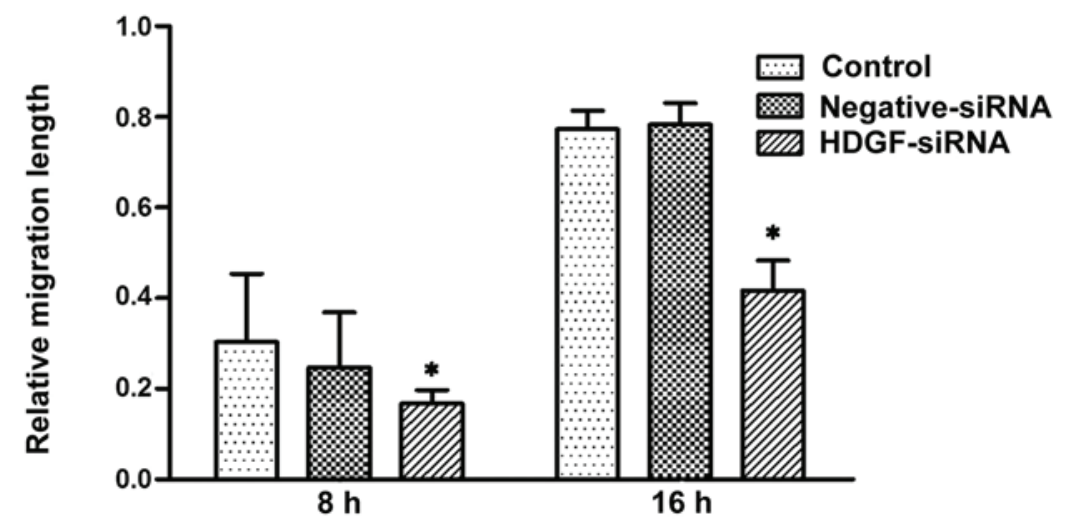

Figure 2. A wound healing migration assay was performed to determine the migratory ability of the cells prior to and following transfection with HDGF siRNA. (A) Representative images of the wound healing assay (magnification, x200). (B) No significant differences were observed between the migration of the cell groups at $8 \mathrm{~h}$ post-HDGF siRNA transfection. However, the migration ability of the HDGF siRNA group decreased significantly at $16 \mathrm{~h}$ post-transfection and was $41.7 \%$ of that observed in the control cells (" $\mathrm{P}<0.05)$. Data are presented as the mean \pm standard deviation. HDGF, hepatoma-derived growth factor; siRNA, small interfering RNA.

groups revealed that the secretion of VEGF was significantly inhibited by HDGF siRNA, the level of which was $66.51 \%$ of that observed in the control supernatant $(\mathrm{P}<0.001$; Fig. 4$)$.

\section{Discussion}

The potential capacities of malignant tumors, including sustaining proliferative signaling, enabling replicative immortality, inducing angiogenesis, and activating invasion and metastasis, make its therapeutic strategies more complicated and difficult (14). Therefore, identifying and screening potential molecular targets or tumor biomarkers involved in one or more malignant processes is beneficial for tumor diagnosis and therapy, and for improving patient survival rates and prognosis.

As a nuclear-targeted mitogen, HDGF has mitogenic activity for various cells following translocation into the nucleus, including hepatic, gastric, lung cancer cells, fibroblasts, endothelial cells, smooth muscle cells and neuronal cells $(7,15-20)$. The downregulation of HDGF suppresses cancer cell growth and invasion, induces apoptosis, and may function as a tumor survival factor $(21,22)$. Previously, a systematic proteomic investigation of human metastatic hepatocellular carcinoma (HCC) cell lines demonstrated that the HDGF protein was one of the metastasis-associated proteins, and that knockdown of HDGF induced cell apoptosis in metastatic HCC cells (23). Therefore, HDGF may act as an oncogene, being important in tumor pathogenesis and progression, and may be a key target for future therapy. However, the roles of HDGF protein in the malignant biological behaviors of the human hilar cholangiocarcinoma cell line, including proliferation, migration, invasion and angiogenesis remain to be elucidated.

Tumorigenesis and progression is the result of cell proliferation and apoptosis in a condition of disequilibrium (24). Several studies have indicated that, following nuclear translocation, HDGF promotes the proliferation of numerous tumor cells, whereas HDGF interference, knockdown or neutralizing antibodies significantly increase the rate of apoptosis 
A

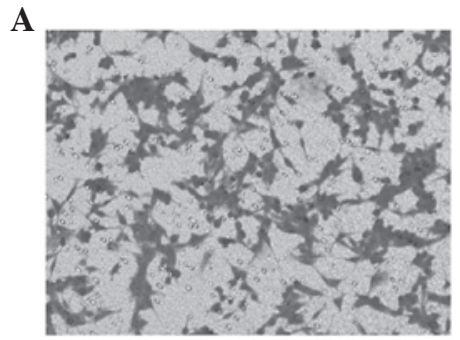

D

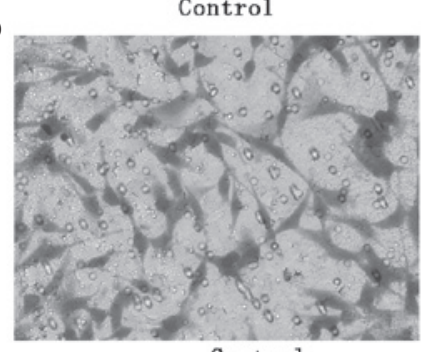

Control

G

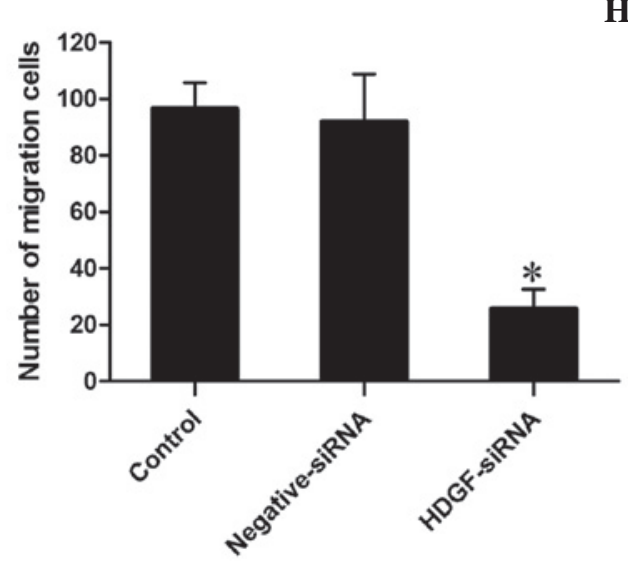

H
B

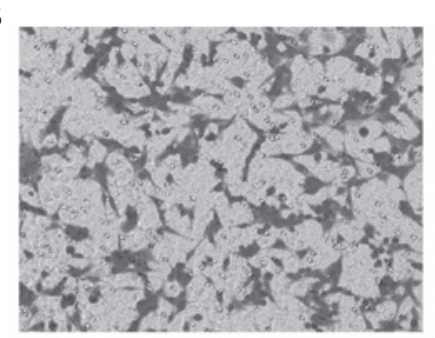

$\mathbf{E}$

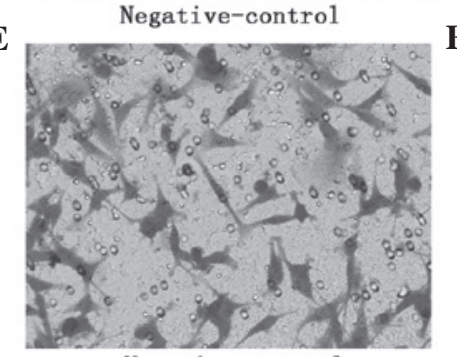

Negative-control
C

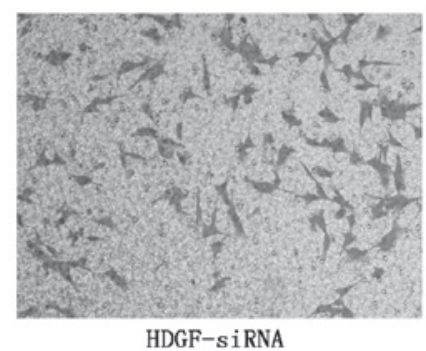

F

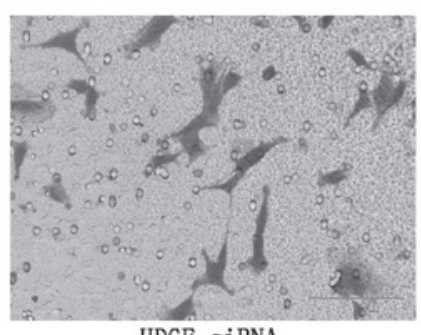

HDGF- $s$ iRNA

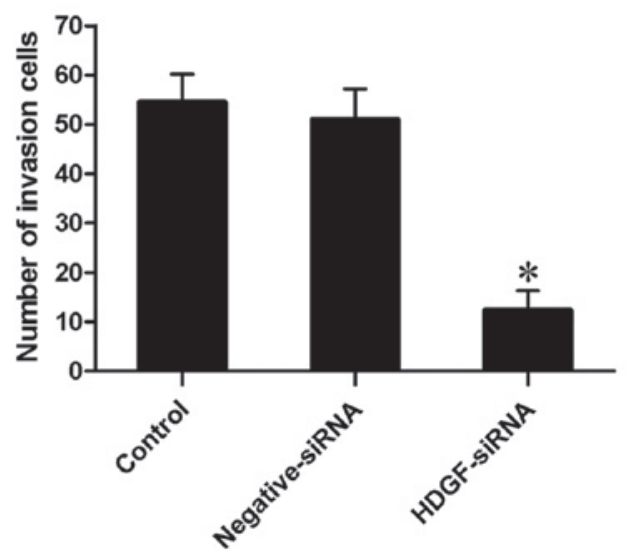

Figure 3. Downregulation of the expression of HDGF inhibits the migration and invasive abilities of the FRH0201 cells. (A-C) Representative images of the Transwell migration assay. (A) Control FRH0201 cells; (B) negative-siRNA FRH0201 cells; (C) HDGF-siRNA FRH0201 cells. (D-F) Representative images of the Transwell invasion assay (D) Control FRH0201 cells; (E) negative-siRNA FRH0201 cells; (F) HDGF-siRNA FRH0201 cells. (G) Transwell migration assay in three-dimensional culture medium demonstrated that the migration of the cells transfected with HDGF siRNA was inhibited, being $26.5 \%$ of that observed in the control cells ( $\mathrm{P}<0.01)$. (H) Transwell invasion assay revealed that the invasive ability of the cells transfected with HDGF siRNA was inhibited, being $22.7 \%$ of that observed in the control cells ( $\left.{ }^{*} \mathrm{P}<0.01\right)$. Data are presented as the mean \pm standard deviation. HDGF, hepatoma-derived growth factor; siRNA, small interfering RNA.

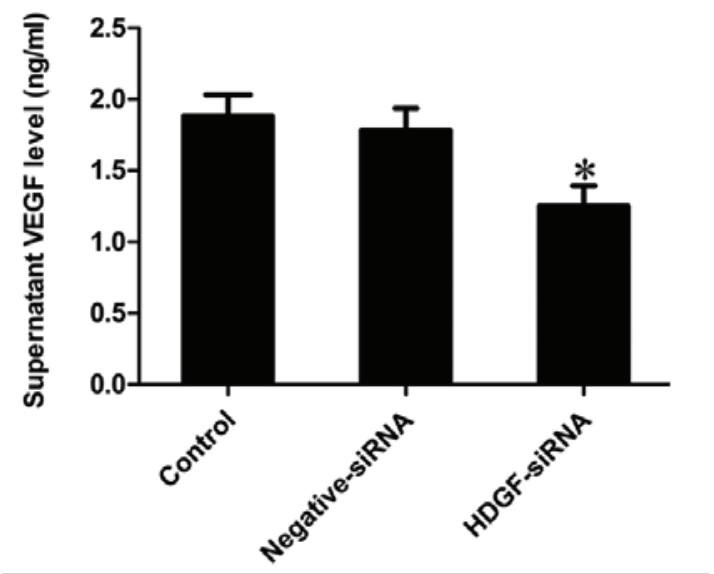

Figure 4. Levels of VEGF in the supernatants revealed that the secretion of VEGF was significantly inhibited by HDGF siRNA, with levels being $66.51 \%$ of those observed in the control supernatant $\left({ }^{*} \mathrm{P}<0.001\right)$. Data are presented as the mean \pm standard deviation. HDGF, hepatoma-derived growth factor; siRNA, small interfering RNA; VEGF, vascular endothelial growth factor. and inhibit proliferation (25-27). The results of the present study demonstrated that, following downregulation of the HDGF protein by HDGF siRNA, the proliferative capacity of the FRH0201 cells was significantly decreased.

Tumor cell migration, invasion and metastasis is a complicated process involving multiple steps and factors (28). Although primary tumors can be effectively controlled or cured with surgery, radiotherapy, chemotherapy and other local therapies, these methods fail to manipulate disease progression for disseminated tumors, which is an important cause of malignancy-associated mortality (29). Therefore, inhibiting the process of tumor cell migration and invasion is an important therapeutic strategy. Previous studies have demonstrated that knockdown of the expression of HDGF inhibits tumor cell migration and invasion in hepatic, lung and prostate carcinoma $(12,21,30)$. Our previous study demonstrated that tumor tissues with high expression levels of HDGF exhibit increased invasive abilities, compared with tissues expressing a low level HDGF. Similarly, patients with 
increased expression of HDGF have been observed to have a significantly poorer outcome, compared with those exhibiting low expression levels of HDGF (31). In the present study it was confirmed that inhibition of the protein expression of HDGF significantly decreased the migration and invasion of FRH0201 cells.

It is generally accepted that tumor growth, invasion and metastasis require angiogenesis, and that vascularization is closely associated with tumor invasion and patient prognosis (32). HDGF, a member of the heparin-binding growth factor family, exhibits a wide range of biological functions and can promote tumor neovascular formation and development as a potential endothelial mitogen $(19,33)$. Previous studies have demonstrated that high expression levels of HDGF activate the extracellular signal-regulated kinase pathway and upregulate the secretion of VEGF (34-36). In addition, another study revealed that HDGF is a potent endothelial mitogen in vivo and regulates endothelial cell migration by mechanisms distinct from VEGF (11). Okuda et al (37) reported that HDGF-induced tumor formation and angiogenesis in vivo involves the direct angiogenic activity and induction of VEGF secretion. In the present study downregulation of the expression of HDGF decreased the secretion of VEGF, which demonstrated that HDGF may induce angiogenesis partially by the action of VEGF.

In conclusion, the present study demonstrated that HDGF was important in promoting the malignant biological behaviors (proliferation, migration and invasion) of the FRH0201 hilar cholangiocarcinoma cell line, and inhibition of the expression of HDGF downregulated the malignant biological behaviors. These results provide novel insights and indicate the potential clinical use of HDGF as an effective therapeutic target for hilar cholangiocarcinoma by inhibiting proliferation, migration and invasion of cancer cells. Further investigation of the mechanism underlying the action of HDGF in hilar cholangiocarcinoma is required.

\section{Acknowledgements}

This study was supported by the Promotive Research fund for Excellent Young and Middle-aged Scientisits of Shandong Province (grant. no. BS2013YY029), the Natural Science Foundation of China (grant. no. 81302123) and the China Postdoctoral Science Foundation funded project (grant. nos. 201003781 and 20080441310).

\section{References}

1. KhansA, Thomas HC, Davidson BR and Taylor-Robinson SD: Cholangiocarcinoma. Lancet 366: 1303-1314, 2005.

2. Ortner MA and Dorta G: Technology insight: Photodynamic therapy for cholangiocarcinoma. Nat Clin Pract Gastroenterol Hepatol 3: 459-467, 2006.

3. Zhang BY, Lu Y, Dong Q, Sun CD and Mu P: Surgical treatment and prognostic analysis of 93 cases of hilar cholangiocarcinoma. Am J Med Sci 339: 221-224, 2010.

4. Jarnagin WR, Fong Y, DeMatteo RP, Gonen M, Burke EC, Bodniewicz BS J, Youssef BA M, Klimstra D and Blumgart LH: Staging, resectability and outcome in 225 patients with hilar cholangiocarcinoma. Ann Surg 234: 507-517; discussion $517-519,2001$.

5. Patel T: Cholangiocarcinoma. Nat Clin Pract Gastroenterol Hepatol 3: 33-42, 2006.
6. Jarnagin WR and Shoup M: Surgical management of cholangiocarcinoma. Semin Liver Dis 24: 189-199, 2004.

7. Nakamura H, Izumoto $\mathrm{Y}$, Kambe H, Kuroda T, Mori T, Kawamura K, Yamamoto $\mathrm{H}$ and Kishimoto T: Molecular cloning of complementary DNA for a novel human hepatoma-derived growth factor. Its homology with high mobility group-1 protein. J Biol Chem 269: 25143-25149, 1994.

8. Nakamura H, Kambe H, Egawa T, Kimura Y, Ito H, Hayashi E, Yamamoto H, Sato J and Kishimotos: Partial purification and characterization of human hepatoma-derived growth factor. Clin Chim Acta 183: 273-284, 1989.

9. Okuda Y, Nakamura H, Yoshida K, Enomoto H, Uyama $\mathrm{H}$, Hirotani T, Funamoto M, Ito H, Everett AD, Hada T, et al: Hepatoma-derived growth factor induces tumorigenesis in vivo through both direct angiogenic activity and induction of vascular endothelial growth factor. Cancer Sci 94: 1034-1041, 2003.

10. Zhang J, Ren H, Yuan P, Lang W, Zhang L and Mao L: Down-regulation of hepatoma-derived growth factor inhibits anchorage-independent growth and invasion of non-small cell lung cancer cells. Cancer Res 66: 18-23, 2006.

11. Everett AD, Narron JV, Stoops T, Nakamura H and Tucker A: Hepatoma-derived growth factor is a pulmonary endothelial cell-expressed angiogenic factor. Am J Physiol Lung Cell Mol Physiol 286: L1194-L1201, 2004.

12. Guo Z, He Y, Wang S, Zhang A, Zhao P, Gao C and Cao B: Various effects of hepatoma-derived growth factor on cell growth, migration and invasion of breast cancer and prostate cancer cells. Oncol Rep 26: 511-517, 2011.

13. Livak KJ and Schmittgen TD: Analysis of relative gene expression data using real-time quantitative PCR and the 2(-Delta Delta C(T)) method.. Methods 25: 402-408, 2001.

14. Hanahan D and Weinberg RA: Hallmarks of cancer: The next generation. Cell 144: 646-674, 2011.

15. Everett AD and Bushweller J: Hepatoma derived growth factor is a nuclear targeted mitogen. Curr Drug Targets 4: 367-371, 2003.

16. Everett AD, Stoops T and McNamara CA: Nuclear targeting is required for hepatoma-derived growth factor-stimulated mitogenesis in vascular smooth muscle cells. J Biol Chem 276: 37564-37568, 2001.

17. Kishima Y, Yamamoto H, Izumoto Y, Yoshida K, Enomoto H, Yamamoto M, Kuroda T, Ito H, Yoshizaki K and Nakamura H: Hepatoma-derived growth factor stimulates cell growth after translocation to the nucleus by nuclear localization signals. J Biol Chem 277: 10315-10322, 2002.

18. Zhou Z, Yamamoto Y, Sugai F, Yoshida K, Kishima Y, Sumi H, Nakamura $\mathrm{H}$ and Sakodas: Hepatoma-derived growth factor is a neurotrophic factor harbored in the nucleus. J Biol Chem 279: 27320-27326, 2004.

19. Everett AD, Lobe DR, Matsumura ME, Nakamura $H$ and McNamara CA: Hepatoma-derived growth factor stimulates smooth muscle cell growth and is expressed in vascular development. J Clin Invest 105: 567-575, 2000.

20. Ooi BN, Mukhopadhyay A, Masilamani J, Do DV, Lim CP, Cao XM, Lim IJ, Mao L, Ren HN, Nakamura $\mathrm{H}$, et al: Hepatoma-derived growth factor and its role in keloid pathogenesis. J Cell Mol Med 14: 1328-1337, 2010.

21. Meng J, Xie W, Cao L, Hu C and Zhe Z: shRNA targeting HDGF suppressed cell growth and invasion of squamous cell lung cancer. Acta Biochim Biophys Sin (Shanghai) 42: 52-57, 2010.

22. Tsang TY, Tang WY, Tsang WP, Co NN, KongsK and Kwok TT: Mechanistic study on growth suppression and apoptosis induction by targeting hepatoma-derived growth factor in human hepatocellular carcinoma HepG2 cells. Cell Physiol Biochem 24: 253-262, 2009.

23. Yu Y, Shen H, Yu H, Zhong F, Zhang Y, Zhang C, Zhao J, Li H, Chen J, Liu Y, et al: Systematic proteomic analysis of human hepotacellular carcinoma cells reveals molecular pathways and networks involved in metastasis. Mol Biosyst 7: 1908-1916, 2011.

24. Carson DA and Ribeiro JM: Apoptosis and disease. Lancet 341: $1251-1254,1993$.

25. Tsang TY, Tang WY, Tsang WP, Co NN, KongsK and Kwok TT: Downregulation of hepatoma-derived growth factor activates the Bad-mediated apoptotic pathway in human cancer cells. Apoptosis 13: 1135-1147, 2008. 
26. Ren $\mathrm{H}$, Chu $\mathrm{Z}$ and Mao L: Antibodies targeting hepatoma-derived growth factor as a novel strategy in treating lung cancer. Mol Cancer Ther 8: 1106-1112, 2009.

27. Liao F, Dong W and Fan L: Apoptosis of human colorectal carcinoma cells is induced by blocking hepatoma-derived growth factor. Med Oncol 27: 1219-1226, 2010.

28. Sahai E: Mechanisms of cancer cell invasion. Curr Opin Genet Dev 15: 87-96, 2005.

29. Valastyans and Weinberg RA: Tumor metastasis: Molecular insights and evolving paradigms. Cell 147: 275-292, 2011.

30. Zhou Y, Zhou N, Fang W and Huo J: Overexpressed HDGF as an independent prognostic factor is involved in poor prognosis in Chinese patients with liver cancer. Diagn Pathol 5: 58, 2010

31. Liu YF, Zhao R, Guo S, Wang XQ, Lian PL, Chen YG and Xu KS: Expression and clinical significance of hepatoma-derived growth factor as a prognostic factor in human hilar cholangiocarcinoma. Ann Surg Oncol 18: 872-879, 2011.

32. Maeda K, Chung YS, Takatsukas, Ogawa Y, Sawada T, Yamashita Y, Onoda N, Kato Y, Nitta A, Arimoto Y, et al: Tumor angiogenesis as a predictor of recurrence in gastric carcinoma. J Clin Oncol 13: 477-481, 1995.
33. Oliver JA and Al-Awqati Q: An endothelial growth factor involved in rat renal development. J Clin Invest 102: 1208-1219, 1998.

34. Mao J, Xu Z, Fang Y, Wang H, Xu J, Ye J, Zhengs and Zhu Y: Hepatoma-derived growth factor involved in the carcinogenesis of gastric epithelial cells through promotion of cell proliferation by Erk1/2 activation. Cancer Sci 99: 2120-2127, 2008.

35. Lee KH, Choi EY, Kim MK, Lee SH, Jang BI, Kim TN, KimsW, KimsW, SongsK, Kim JR, et al: Hepatoma-derived growth factor regulates the bad-mediated apoptotic pathway and induction of vascular endothelial growth factor in stomach cancer cells. Oncol Res 19: 67-76, 2010.

36. Ooi BN, Mukhopadhyay A, Masilamani J, Do DV, Lim CP, Cao XM, Lim IJ, Mao L, Ren HN, Nakamura $\mathrm{H}$, et al: Hepatoma-derived growth factor and its role in keloid pathogenesis. J Cell Mol Med 14: 1328-1337, 2010.

37. Okuda Y, Nakamura H, Yoshida K, Enomoto H, Uyama H, Hirotani T, Funamoto M, Ito H, Everett AD, Hada T, et al: Hepatoma-derived growth factor induces tumorigenesis in vivo through both direct angiogenic activity and induction of vascular endothelial growth factor. Cancer Sci 94: 1034-1041, 2003. 